\title{
Software educativo en línea para la enseñanza y el aprendizaje de temas de Cálculo Numérico
}

Eva M. Ascheri mavacheri@gmail.com Universidad Nacional de La Pampa, Argentina
Rubén Pizarro rubenpizarro71@gmail.com

Universidad Nacional de La Pampa, Argentina astudillo@exactas.unlp
Nacional de La $\mathrm{P}$

\author{
Pablo García \\ pablogarcia.Ip@gmail.com \\ Universidad Nacional de La \\ Pampa, Argentina
}

Recibido: Mayo 14, 2013

\author{
M. Eugenia Culla \\ eugeculla@hotmail.com \\ Universidad Nacional de La \\ Pampa, Argentina
}

Aceptado: Febrero 18, 2014

Resumen. En un proyecto de investigación finalizado, se diseñó un software de escritorio para la enseñanza y el aprendizaje del tema Resolución Numérica de Ecuaciones no Lineales, usando el paquete MatLab. Considerando los resultados obtenidos, se propuso elaborar un software educativo que incluyera, además de ese contenido, los temas Interpolación y Aproximación Polinomial y Ajuste de Curvas por Mínimos Cuadrados, pero ahora utilizando software libre y con la condición de que fuera accesible directamente desde la Web.

Se busca que este nuevo software actúe como herramienta de soporte para el desarrollo del curso de Cálculo Numérico y que los estudiantes dispongan de una aplicación educativa, disponible en la Web y de acceso libre.

El artículo presenta una descripción del software, sus principales características y los resultados obtenidos en el proceso de evolución del mismo.

Palabras clave: Software educativo, software libre, Cálculo Numérico. 
Abstract. In a previous research project, a desktop software for teaching and learning Numerical SolutionS of Nonlinear Equations was designed using MatLab. Considering the results, it was proposed to elaborate an educational software which included other topics such as Polynomial Interpolation and Approximation, and Curve Fitting by Minimal Squares, but this time using free tools accesible on the Web. This new software aims to acts as a support tool for the development of any Numerical Calculus course and, simultaneously, provide students with a free web application for learning. In this work, we present the evolution of the software, its main characteristics and results reached from the implementations that were developed.

KeyWords: Educational software, open software, Numerical Calculus.

\subsection{Introducción}

En el año 2007, se emprendieron las actividades de investigación realizando una búsqueda y estudio sobre el material disponible en la Web. Se centró la indagación en aplicaciones educativas que utilizaran herramientas libres y gratuitas en un entorno Web, y que incluyesen las temáticas que se abordan en un curso de Cálculo Numérico.

La diversidad de los temas que abarca la currícula de Cálculo Numérico que se dicta en la Facultad de Ciencias Exactas y Naturales de la Universidad Nacional de La Pampa, Argentina, hizo difícil la elección de aquellos que se incluirían en el software educativo que se quería elaborar. Ahora bien, de la experiencia lograda a partir del desarrollo de un Proyecto de Investigación anterior (Ascheri y Pizarro, 2005 y 2006; Pizarro y Ascheri, 2007), de la búsqueda y análisis del material disponible en línea sobre las temáticas que se abordan en un curso de Cálculo Numérico (Ascheri et al, 2007) y dando prioridad a aquellos contenidos que, sistemáticamente, resultaban de más difícil comprensión para los estudiantes que se matriculaban en este curso (Ascheri y Pizarro, 2007), se incluyeron entonces los temas: Resolución Numérica de Ecuaciones no Lineales, Interpolación y Aproximación Polinomial y Ajuste de Curvas por Mínimos Cuadrados. Asimismo, se decidió que incorporar lavisualización gráfica del comportamiento de los métodos numéricos correspondientes sería un objetivo prioritario y central en el proyecto. Los temas seleccionados forman parte del curso de Cálculo Numérico que se dicta para las carreras de Profesorado en Matemática (3 Año), Licenciatura en Física (3 Año) e Ingeniería Civil (2 Año).

En el Proyecto de Investigación anterior se desarrolló un software educativo para algunos temas de Cálculo Numérico, utilizando como herramienta el paquete MatLab (Ascheri y Pizarro, 2005 y 2006; Pizarro y Ascheri, 2007). Institucionalmente, un inconveniente en el uso de ese software era el costo de dicho paquete, indispensable para ejecutarlo. La experiencia obtenida a partir de la estrategia metodológica empleada en ese Proyecto, motivó que se continuara trabajando en la misma línea, en un nuevo Proyecto, elaborando un software educativo con herramientas libres, que incluyera varias temáticas de Cálculo Numérico y estuviera disponible en la Web. Todo ello con vistas a:

- lograr una integración curricular y complementar los resultados obtenidos hasta el momento,

- guiar el aprendizaje de los estudiantes como soporte a la explicación del profesor, y

Software educativo en línea.... Ascheri, M. et al

Derechos Reservados @ 2014 Revista digital Matemática, Educación e Internet (www.tec-digital.itcr.ac.cr/revistamatematica/) 
- tener acceso libre y gratuito en un entorno Web.

Esta aplicación debía cumplir requerimientos mínimos y permitir su uso como herramienta para la enseñanza y el aprendizaje de métodos numéricos, donde se mostrase de forma numérica y gráfica el comportamiento de los mismos. Se comenzó a elaborar el primer prototipo diseñado en el lenguaje de programación $\mathrm{PHP}^{1}$ y con la biblioteca JPGRAPH ${ }^{2}$.

\subsection{Marco conceptual}

Para definir y clasificar a los programas educativos, Squires y Mc Dougall (1994) hacen una revisión de un conjunto de marcos de referencia que agrupan en clasificación por tipo de aplicación, por su función educativa y por su fundamentación educativa. En la primera clasificación, se distinguen dos tipos de software educativos:

- El carente de contenidos: Es aquél que sin ser diseñado con una intencionalidad pedagógica es adaptado por el docente para sus clases.

- El software específico para una asignatura/temática: Es aquél que es diseñado específicamente para la enseñanza y el aprendizaje de un tema concreto o de una asignatura. No hay acuerdo entre los autores en una taxonomía exacta, pero se propone: (i) Ejercitación, (ii) tutoriales, (iii) bases de datos, $(i v)$ simulaciones, $(v)$ juegos y (vi) inteligencia artificial.

Si bien este enfoque brinda una manera sencilla de clasificar las aplicaciones educativas, es muy sensible al paso del tiempo. Las nuevas aplicaciones no encajan exactamente en la taxonomía, ya que presentan características acordes a más de una clasificación.

La clasificación por su función educativa, hace hincapié en la función del software. No se tienen en cuenta las necesidades de los estudiantes ni las del docente; el diseñador crea la aplicación en función de lo que él cree que debería hacer el software. Este enfoque se vuelve riesgoso cuando es utilizado para el diseño de software educativo, ya que es necesario tener en cuenta el perfil del estudiante. Además, rompe con un principio básico del propio diseño de software: tener en cuenta al usuario.

Por su parte, Rodino (1996) expresa que Sancho Gil divide en tres grupos las funciones que pueden desempeñar las aplicaciones computacionales en la enseñanza:

- Aplicaciones destinadas a la ejercitación: el tipo de aprendizaje propuesto es estímulo-respuesta por repetición.

- Aplicaciones que permiten la verificación de hipótesis y la resolución de problemas: el aprendizaje es por descubrimiento y resolución de problemas.

- Aplicaciones que permiten el análisis de problemas: el aprendizaje que estimulan es por procesamiento significativo de la información.

$1 \quad$ PHP es un lenguaje de scripting de propósito general ampliamente utilizado. Es especialmente adecuado para el desarrollo Web y puede ser embebido en páginas HTML (The PHP Group, 2013).

2 JpGraph es una librería para PHP que provee importantes funcionalidades en el manejo de gráficos estadísticos. Es gratuita para uso educativo. Disponible en: http://jpgraph.net/ 
Independientemente de las habilidades cognitivas que estimulen las actividades propuestas en la aplicación, siempre es posible que los estudiantes cometan errores. Los mismos podrían deberse a una incorrecta operación de la aplicación o a una manera inapropiada de aplicar su conocimiento. Por lo tanto, un aspecto muy importante a tener en cuenta al diseñar un software es el tratamiento que se le dará al error.

Según Sternberg (1982), los errores son ventanas que permiten observar el proceso a través del cual se realiza una tarea. De allí la importancia de tenerlos en cuenta al momento de diseñar una aplicación educativa. Si bien los errores al operar un software pueden devenir de la falta de conocimiento o experiencia en el manejo del mismo, y éstos deben ser previstos y tratados por el programador, se prestó máxima atención a aquellos errores que tienen que ver con el proceso de aprendizaje.

Hasta el momento se ha hablado de software educativo en general. Pero existe una ciencia a la que el software la ha acompañado desde sus inicios, la matemática. Como escribe Villegas (2007, p. 149), "para trabajar las matemáticas, el ser humano siempre ha necesitado de herramientas que le faciliten la representación y comprensión de los conceptos o le permitan aumentar la rapidez de cálculo". Esto se aplica directamente a las computadoras, que ya atraviesan todos los aspectos de la vida diaria, y lo hacen particularmente en la matemática. La computadora nace como herramienta de cálculo para posteriormente evolucionar hasta lo que conocemos hoy en día. Y, en esa evolución, siempre necesitó a la matemática y ésta a la computadora. Desde la criptografía, pasando por las hojas de cálculo, hasta llegar a demostradores de teoremas. Al estar tan ligadas la matemática y las computadoras, estas últimas no podían estar ajenas a los procesos de enseñanza y aprendizaje de la matemática. Dice Santandreu (2004, p. 65), "el uso de los recursos tecnológicos favorece un aprendizaje más eficiente en los alumnos e influyen sobre qué matemáticas enseñar y cómo hacerlo, son instrumentos de mediación en la construcción y estructuración del conocimiento matemático, suministran un nuevo ambiente de aprendizaje". En este sentido, Quintana Mendoza y Mendoza Bolo (2006, p. 41) afirman que "con apoyo de las computadoras se pueden adquirir conocimientos matemáticos que con la pizarra, tizas, papel o lápices sería muy limitado y poco agradable a la vista de los estudiantes".

Dentro del software disponible para matemática, se puede plantear una división en diferentes categorías. Autores como Losada Liste (2007) y Zhao (1998), plantean clasificar las aplicaciones matemáticas de acuerdo a la temática o área de conocimiento que abordan, a saber:

- Sistemas de Álgebra Computacional (CAS)

- Sistema para Cálculo Numérico (NCS)

- Sistemas de Geometría Dinámica (DGS)

- Demostradores Automáticos de Teoremas (APS)

- Graphics and data analysis systems/Paquetes Estadísticos (GDAS)

- Symbolic Calculators/Sistemas de Cálculo Simbólico (SC)

- Software Educativo para Matemática (MES).

Como toda clasificación, corre el riesgo de la obsolescencia y, en consecuencia, que nuevos software queden fuera o bien que aparezcan aplicaciones que pueden ser categorizadas en más de un clasificador. Además, la clasificación para software educativo (MES) es un tanto general, y se cree que debiera ser asumida como transversal a las demás. 
En lo que se refiere a software educativo para abordar temas de Cálculo Numérico, se pueden encontrar en la Web diversas aplicaciones de acceso libre y gratuito. Entre ellas, la elaborada por Mora (2011) que cubre los contenidos temáticos que se abordan en esta investigación. Con respecto a la aplicación desarrollada por este autor, el software educativo de elaboración propia presenta las siguientes características adicionales:

- Para la resolución de ecuaciones no lineales contiene además, los métodos de von-Míses y secante. Por otro lado, muestra paso a paso (para cada iteración) cómo trabaja cada método en forma numérica y gráfica.

- En lo que se refiere a interpolación contiene además, el polinomio de interpolación de Lagrange. Tratándose de este tema, también permite el ingreso de una función conocida.

- Incluye el ajuste de curvas por mínimos cuadrados.

- En todos los casos, contiene ayudas de los contenidos temáticos que se abordan y acerca del uso del software.

Otras de las aplicaciones disponibles en la Web que incluye los contenidos involucrados en esta investigación es Solve My Math (2006-2012). El software educativo presentado en este trabajo contempla las siguientes características adicionales:

- Para la resolución de ecuaciones no lineales contiene varios métodos numéricos, mientras que no se puede inferir nada acerca del o de los métodos que usa Solve My Math). Por otro lado, muestra paso a paso cómo trabaja cada método en forma numérica y gráfica.

- En lo que se refiere a interpolación contiene además, el polinomio de interpolación de Newton. Tratándose de este tema, también permite el ingreso de una función conocida.

- Incluye el ajuste de curvas por mínimos cuadrados.

- En todos los casos, contiene ayudas de los contenidos temáticos que se abordan y acerca del uso del software.

También en el Imperio del número, herramientas matemáticas (2013), se aborda la temática Resolución de ecuaciones no lineales. Si bien este software resuelve rápidamente diversas ecuaciones, no es factible ver qué tipo de método numérico utiliza así como tampoco visualizar su solución gráficamente.

Análogamente, se podrían citar otros software que involucran el tratamiento de temas de Cálculo Numérico y hacer, luego, una breve síntesis acerca de su funcionamiento. No obstante ello, en líneas generales, se puede afirmar que las aplicaciones que se encuentran en la Web, de acceso libre y gratuito, muestran una tendencia a la obtención de resultados numéricos más que a la visualización gráfica de la forma exacta sobre cómo el método funciona. Esto es, se prioriza la resolución en sí misma por sobre el aprendizaje de la técnica numérica empleada, alejándose así del objetivo central de esta investigación, que es visualizar gráficamente el comportamiento de los métodos numéricos incorporados al software educativo. Claro está, además de obtener la resolución numérica del problema a tratar, de incluir las ayudas teóricas correspondientes y de presentar un alto nivel de interacción entre usuario y software. Por otra parte, en el contexto de la clasificación de software, se puede hablar también de software libre y de software propietario. En la primera categoría, entran aquellos programas que permiten al usuario ejecutar, estudiar, redistribuir y mejorar el software. Y en la segunda categoría, se encuentran aquellos que pueden exigir la compra de una licencia para su utilización (Gómez Sánchez, 2004). 


\subsection{Evolución de los primeros prototipos del software}

Teniendo como experiencia previa el software educativo elaborado en MatLab, se comenzó con el desarrollo de este nuevo software utilizando las herramientas libres ya mencionadas. Al igual que en la versión anterior, en su primer prototipo, se implementaron seis métodos para resolver numéricamente ecuaciones no lineales: los métodos de bisección, secante, regula falsi, iterativo de punto fijo, Newton y von Mises (Ascheri et al, 2008). En la Figura 1.1, se muestra una imagen de la primera pantalla del software.

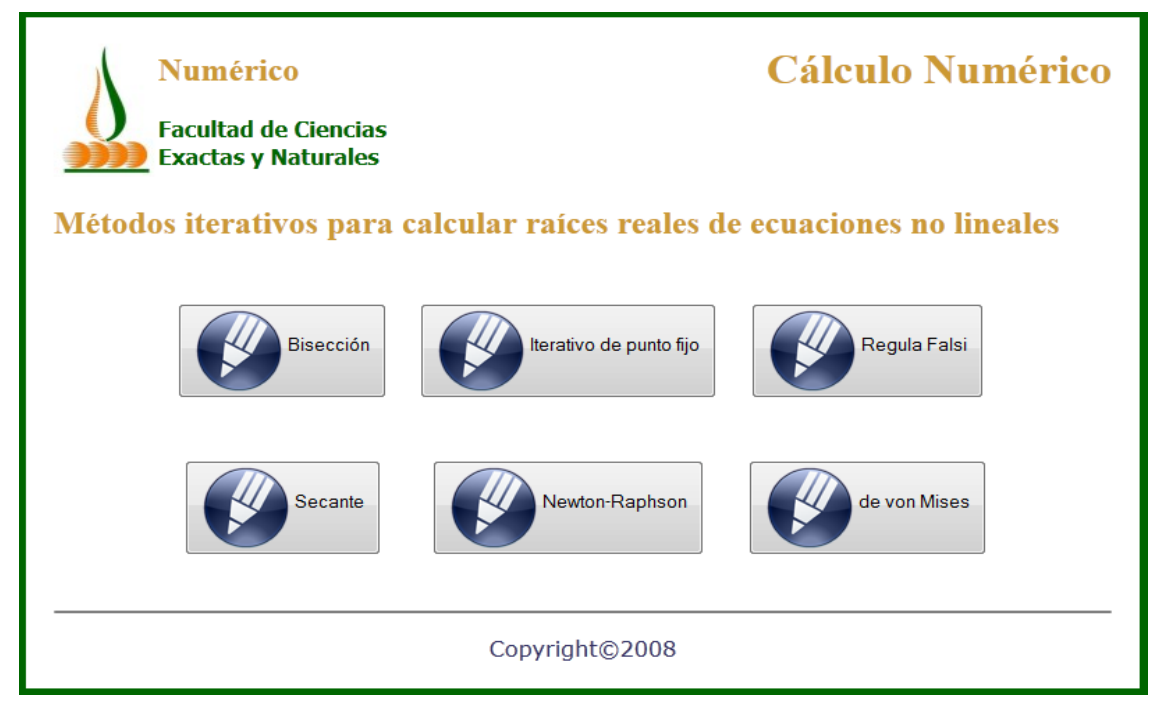

Figura 1.1: Página principal del primer prototipo

A partir de este prototipo, se hace una primera evaluación del software para descubrir posibles errores al usarlo. Esta evaluación permitió detectar debilidades y fortalezas de la aplicación y generar un segundo prototipo, el cual se muestra en la Figura 1.2 (Ascheri et al, 2009).

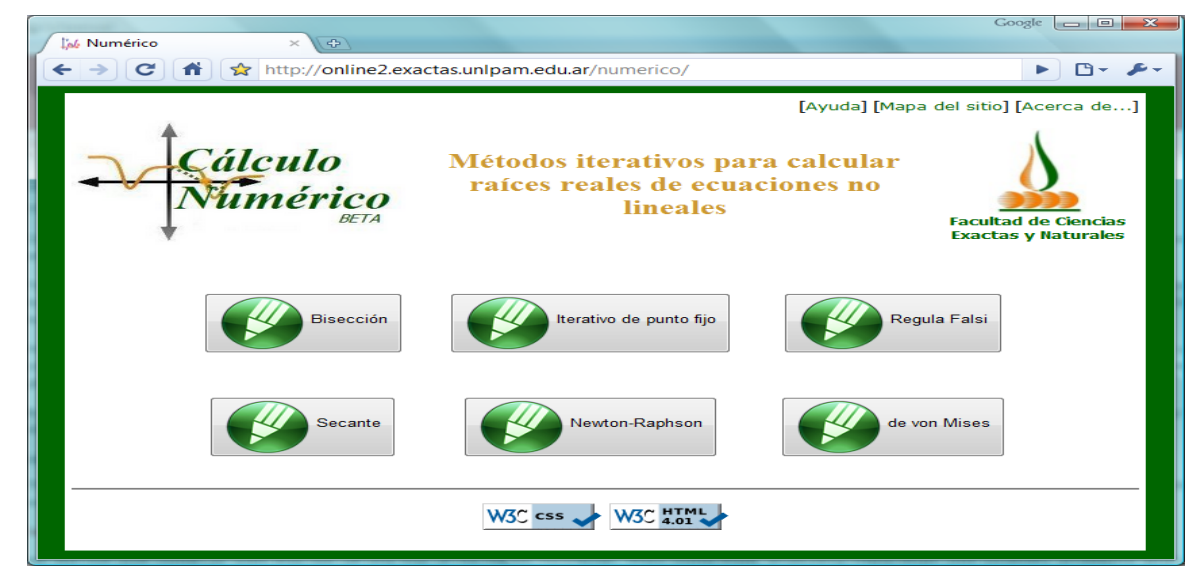

Software educativo en línea.... Ascheri, M. et al

Derechos Reservados ( 2014 Revista digital Matemática, Educación e Internet (www.tec-digital.itcr.ac.cr/revistamatematica/) 
Figura 1.2: : Página inicial del segundo prototipo

Luego, en etapas posteriores (Ascheri et al, 2010, 2011), se desarrollaron tareas relacionadas con:

- La evaluación del impacto que produce el uso del software educativo elaborado para el proceso de enseñanza y aprendizaje de temas de Cálculo Numérico.

- El desarrollo de los métodos que completan la propuesta inicial.

Para la elaboración de estos prototipos se observó, principalmente, un aspecto importante para el análisis y diseño de software, la interfaz.

Según Marquès (1996), la interfaz es el entorno a través del cual los programas establecen el diálogo con sus usuarios y es la que posibilita la interactividad característica de estos materiales.

Son varios los aspectos a tener en cuenta al momento de diseñar la interfaz de usuario. Pero como se debía analizar una aplicación Web, el estudio se centró en la usabilidad. La usabilidad se refiere a la capacidad de un software de ser comprendido, aprendido, usado y ser atractivo para el usuario, en condiciones específicas de uso.

La usabilidad tiene dos aspectos centrales, elcontenidoy laestética, y el balance entre ellos es muy importante. La interfaz no debe ser una barrera para poder entender el contenido (Baeza Yates y Rivera Loaiza, 2002).

Para que un software educativo motive al aprendizaje, es fundamental que sea atractivo y de fácil manejo (Díaz Antón et al, 2002). Esto está relacionado directamente con la usabilidad.

En la Web, este parámetro de calidad, toma una relevancia particularmente importante ya que las páginas Web son accedidas por un gran número y variedad de usuarios (estudiantes y educadores, para el caso de un software educativo).

Una parte constitutiva de la Web, y tenida en cuenta en las evaluaciones de usabilidad, es el hipertexto. Si bien podríamos pensar en el hipertexto, simplemente, como la forma en que se puede recorrer un sitio Web, es más que esto. Podemos ver al hipertexto como una forma de definir la estructura del contenido y la manera en que éstos van a llegar a los estudiantes. Según Burbules y Callister (2001), la estructura organizativa del hipertexto puede reflejar la estructura organizativa del tema tratado o de la red semántica de un experto. En un software educativo la red definida por el hipertexto se convierte en un mapa conceptual.

Es posible mediar un documento a través del hipertexto, utilizando la estructuración de los enlaces de manera de mostrar un camino al estudiante o enriqueciendo la propuesta a través de vínculos con otros documentos (Prieto Castillo, 1999). Con el hipertexto aparece la oportunidad de enseñar algo al estudiante, lo que puede parecer caótico y sin una dirección puede ser mediado a través de los enlaces con fines didácticos. Esto es lo que Litwin (2001) denomina re-centración. Es posible marcar un rumbo, marcar una forma de razonamiento o el cómo hacer, pero también es necesario dar la libertad para que el estudiante recorra la red de enlaces utilizando como motor sus conocimientos o su propia curiosidad. 


\subsection{Incorporando el software en el aula: evaluación}

Ante la disponibilidad de los primeros prototipos del software educativo y su puesta en práctica, se realizó su evaluación. Se analizaron los errores y aciertos, se realizaron ajustes y se aplicó en clases en reiteradas oportunidades. Se detalla a continuación, las características de la evaluación implementada.

\section{Metodología}

La evaluación de la aplicación se llevó adelante a través de una caminata cognitiva. Es decir, un grupo de expertos simula la manera en cómo un usuario "caminaría" por la interfaz al enfrentarse a tareas particulares (Baeza Yates y Rivera Loaiza, 2002).

Para evaluar la usabilidad de la aplicación se utilizaron heurísticas adaptadas por Instone (1997a, 1997b) para aplicaciones Web de un trabajo de Jakob Nielsen, a saber:

- Visibilidad del estado del sistema.

- Similitud entre el sistema y el mundo real.

- Control por parte del usuario y libertad.

- Consistencia y cumplimiento de estándares.

- Prevención de errores.

- Preferencia al reconocimiento frente a la memorización.

- Flexibilidad y eficiencia de uso.

- Estética y diseño minimalista.

- Ayuda para que el usuario reconozca, diagnostique y se recupere de los errores.

- Ayuda y documentación.

Las heurísticas permitieron rediseñar la aplicación y generar el tercer prototipo (Ascheri et al, 2011). Este fue presentado a los estudiantes en el año 2011 en las prácticas de la asignatura Cálculo Numérico. Se trabajó con la aplicación durante el tiempo que demanda el desarrollo de los trabajos prácticos relativos a la Resolución de Ecuaciones no Lineales y a Interpolación y Aproximación Polinomial (ver Anexo I). El software también fue utilizado en las clases teóricas y en las instancias de evaluación que realiza la cátedra (ver Anexo II).

A continuación, se presentan los resultados de los aspectos de la evaluación de la usabilidad (que hicieron posible generar el segundo prototipo) y de la encuesta realizada a los estudiantes. Estas tareas se llevaron a cabo entre los años 2008 y 2010.

Software educativo en línea.... Ascheri, M. et al

Derechos Reservados @ 2014 Revista digital Matemática, Educación e Internet (www.tec-digital.itcr.ac.cr/revistamatematica/) 


\section{Visibilidad del estado del sistema}

Desde la página de inicio del software (Figura 1.2), seleccionando cualquiera de los métodos indicados se abre una ventana/pestaña nueva. Si bien ello tenía la intención de facilitar la comparación de resultados/comportamientos de varios métodos sobre la misma función, podía producir desorientación a algunos usuarios (léase usuario en los términos de Burbules y Callister, 2001). Este efecto se acentúa en aquellos navegadores que abren nuevas pestañas, ya que es menos notorio la aparición de una nueva pestaña que una ventana. Se pudo observar que la aplicación no mostraba ninguna indicación de cómo volver a la página de inicio. Tampoco mostraba el camino recorrido por el usuario para llegar a la página dónde se encontraba o un mapa del sitio. Ambos recursos deberían ser incorporados para evitar que el usuario se extravíe y así mejorar la usabilidad.

Se observó también que el sistema identificaba los enlaces utilizando texto que al pasar por encima con el mouse se subraya. Esto permitía al usuario identificar las acciones que podía realizar en el sistema, independientemente de la página donde se encontrase.

Cada uno de los métodos contaba en su página de inicio con una imagen que lo ilustraba. En todos los casos se trataba de gráficas de funciones donde el algoritmo ha sido aplicado. Esto podría dar la idea equivocada de que se trataba de la aplicación del método. Se pensó entonces que esta imagen podría ser reemplazada por la figura de los autores de los métodos. Adicionalmente, dichas figuras podrían ser utilizadas como enlaces icónicos a sus biografías. De lo anterior, se concluyó que este aspecto se había cumplido parcialmente.

\section{Similitud entre el sistema y el mundo real}

Se espera que los estudiantes que van a utilizar esta aplicación, grupo clase de Cálculo Numérico, tengan conocimientos de Matemática e Informática al llegar a cursar esta asignatura. Partiendo de esta base, el lenguaje utilizado (tanto gráfico como textual) era adecuado para el tipo de destinatario. En ese sentido, se desarrolló un intérprete cuyo objetivo era que los usuarios ingresen las funciones y los parámetros de la manera que a ellos les resultase natural. Las fórmulas son traducidas a la codificación que utiliza PHP. Si en algún caso estas son ingresadas directamente en formato PHP, también funcionará apropiadamente. De lo anterior, se consideró que este aspecto se había cumplido aceptablemente.

\section{Control por parte del usuario y libertad}

La caminata cognitiva permite afirmar que esta aplicación se maneja al ritmo del usuario quien puede elegir la función, los parámetros con los que desea hacer la gráfica y cuándo aplicar el método. Esto le da al estudiante el control sobre la aplicación y la libertad de elegir qué método aplicar y con qué parámetros, los cuales pueden ser modificados las veces que considere necesarias. Este aspecto se había cumplido aceptablemente.

\section{Consistencia y cumplimiento de estándares}

Para las páginas Web es muy importante que se cumplan los estándares debido a la variedad de navegadores disponibles, como Google Chrome, Microsoft Internet Explorer, Mozilla Firefox, Safari u Opera, W3C, entre otros. Al apegarse la aplicación a los estándares propuestos por la W3C (World Wide Web Consortium $^{3}$ ), los diseñadores pueden garantizar que la página/aplicación se verá adecuadamente en

3 La W3C es un consorcio internacional donde sus miembros trabajan para desarrollar estándares y pautas para la Web que permitan su crecimiento y extraigan de esta su máximo potencial (http://www.w3.org/). 
casi cualquier navegador. Lo que a su vez, implica que los recaudos que se tomaron en el diseño van a estar a disposición de todos los usuarios. Para realizar la evaluación de los estándares, la W3C pone a disposición de los diseñadores Web un servicio de validación de etiquetas (The W3C Markup Validation Service ${ }^{4}$ ) y un servicio de validación de estilos CSS (The CSS Validation Service ${ }^{5}$ ).

Se evaluó la aplicación utilizando ambas herramientas de la W3C y se detectaron sólo dos tipos de errores:

- En el encabezado: La identificación del lenguaje y el juego de caracteres utilizado (español y UTF-8), y el estándar HTML usado (DTD HTML 4.01 Transitional).

- En el cuerpo: A las imágenes les faltaban los modificadores ALT y los VALIGN no pertenecían al estándar.

Es decir, no hay errores en los estilos CSS. Así, se pudo inferir que la aplicación estaba, en general, apegada al estándar W3C. Por lo tanto, se cumplió aceptablemente este aspecto.

\section{Prevención de errores}

La validación y prevención de los errores que pueden surgir a través de la carga de los formularios estaba cubierta en su totalidad y la devolución que hacía el sistema, a través de una ventana pop-up, permitió leer la causa del error con tranquilidad y volver al formulario para resolverlo. Por ello, la prevención de errores era aceptable.

\section{Preferencia al reconocimiento frente a la memorización}

Al navegar el sitio, se pudo observar que las pantallas donde se trabajaba con los distintos métodos numéricos eran muy similares; cambiaban sólo el título y los campos donde se asignan los parámetros que requiere cada método numérico.

Para el ingreso de las funciones se utilizó una sintaxis flexible y estándar para este tipo de aplicaciones. Se apela a símbolos y palabras muy utilizadas en aplicaciones matemáticas. Como ejemplo, se pueden mencionar "sen" o "cos" en las funciones trigonométricas o el acento circunflejo "^ " para la potencia.

Respecto de los datos que el estudiante cargaba en los distintos formularios, los acompañaban al cambiar de página, por lo que no debían memorizarlos. Por ello, este aspecto estaba cubierto aceptablemente.

\section{Flexibilidad y eficiencia de uso}

Si bien son varios los factores que inciden en la rapidez con la que se carga una página, se puede decir que en el caso de las páginas previas a la aplicación de los métodos es muy poco el volumen de información que se transfiere, en su mayoría es código HTML y dos o tres imágenes. En el caso de las páginas donde se visualiza la aplicación de los métodos, se muestra una imagen (en formato PNG) por cada iteración (la cantidad depende de los parámetros). Las imágenes son generadas en el servidor y luego enviadas al usuario. Se estima que sería pertinente en este caso, ofrecer la posibilidad de mostrar o no las gráficas en la solución. Este aspecto se había cumplido parcialmente.

4 Se puede acceder a este servicio en http://validator.w3.org/

5 Se puede acceder a este servicio en http://jigsaw.w3.org/css-validator/ 


\section{Estética y diseño minimalista}

En esta aplicación se podía observar que si bien la solución visual de los métodos propiciaba el aprendizaje de los mismos, el objetivo final de la aplicación era hallar las raíces de una ecuación no lineal. Este dato se encontraba en un cuadro de texto debajo de la secuencia de imágenes que mostraban las iteraciones. Por lo tanto, el usuario que sólo deseaba hallar el valor de la raíz debería esperar que se descarguen todas las imágenes para visualizar el resultado. En consecuencia, sería deseable que este resultado sea movido al inicio de la página.

Por otro lado, como se recomendó en el punto anterior, la aplicación debería dar al usuario la opción de ver o no las imágenes que dan la solución gráfica. Este aspecto se había cumplido parcialmente.

\section{Ayuda para que el usuario reconozca, diagnostique y se recupere de los errores}

Los mensajes de error se expresaron en un lenguaje claro y acorde al tipo de usuario esperado. Este aspecto se había cumplido adecuadamente.

\section{Ayuda y documentación}

El sitio no contaba con una ayuda completa en línea sobre cómo operarlo. Sólo tenía dos páginas que mostraban al usuario la sintaxis de las funciones de los métodos más usados, Newton-Raphson y von Mises. La ayuda y documentación con la que contaba el sitio era insuficiente, máxime tratándose de una aplicación Web. Por lo tanto, este aspecto no se había cumplido.

La Tabla 1.1 muestra un resumen de esta evaluación. En ella se puede apreciar que los niveles de usabilidad alcanzados son buenos. 


\begin{tabular}{|c|c|c|c|}
\hline Aspecto evaluado & $\begin{array}{c}\text { Se cumple } \\
\text { aceptablemente }\end{array}$ & $\begin{array}{l}\text { Se cumple } \\
\text { parcialmente }\end{array}$ & No se cumple \\
\hline $\begin{array}{l}\text { 1. Visibilidad del estado del } \\
\text { sistema }\end{array}$ & & $\checkmark$ & \\
\hline $\begin{array}{l}\text { 2. Similitud entre el sistema } \\
\text { y el mundo real }\end{array}$ & $\checkmark$ & & \\
\hline $\begin{array}{l}\text { 3. Control por parte del } \\
\text { usuario y libertad }\end{array}$ & $\checkmark$ & & \\
\hline $\begin{array}{l}\text { 4. Consistencia y cumplim- } \\
\text { iento de estándares }\end{array}$ & $\checkmark$ & & \\
\hline 5. Prevención de errores & $\checkmark$ & & \\
\hline $\begin{array}{l}\text { 6. Preferencia al re- } \\
\text { conocimiento }\end{array}$ & $\checkmark$ & & \\
\hline $\begin{array}{l}\text { 7. Flexibilidad y eficiencia } \\
\text { de uso }\end{array}$ & & $\checkmark$ & \\
\hline $\begin{array}{l}\text { 8. Estética y diseño minimal- } \\
\text { ista }\end{array}$ & & $\checkmark$ & \\
\hline 9. Ayuda para los errores & $\checkmark$ & & \\
\hline 10. Ayuda y documentación & & & $\checkmark$ \\
\hline
\end{tabular}

Tabla 1.1: Resumen de la evaluación de usabilidad de la aplicación Web

Este análisis dio como resultado un conjunto de pautas que permitieron realizar varias mejoras al software, que van desde una mejor navegabilidad y opciones más claras para facilitar la resolución de los ejercicios y la visualización de los resultados, hasta una visión global (mapa del sitio) de los métodos desarrollados en el curso de Cálculo Numérico, información de sus autores y recomendaciones en la forma que debe utilizarse la aplicación para maximizar el impacto cognitivo.

Continuando con las características de los primeros prototipos, se puede decir que la estructura de los enlaces muestra una intención de clasificación de los métodos numéricos para la resolución de ecuaciones no lineales. Esto se puede observar en la ventana inicial o página de inicio (Figura 2), en la que se muestran al mismo nivel cada uno de los métodos numéricos. La clasificación podría volverse más significativa, si la aplicación contara con un mapa del sitio en forma de árbol o mejor aún, un mapa conceptual que muestre no sólo la estructura del sitio sino también, el lugar que ocupa dentro de la asignatura los métodos para la resolución de ecuaciones no lineales. 
También se muestra, a través del hipertexto, una metodología de trabajo. Los estudiantes, al utilizar la aplicación, deben primero realizar la gráfica de la función y luego aplicar el método numérico elegido. El programa no brinda la posibilidad al usuario de ingresar la función y los parámetros, y obtener directamente la raíz. Propone el análisis de la gráfica y en función de esto el ajuste de los parámetros y, finalmente, la aplicación del método numérico. Si bien este análisis no permite comprobarlo, se puede afirmar que esta metodología propuesta a través de los enlaces puede dejar un residuo cognitivo en los estudiantes. Esto es, que puedan utilizar esta metodología en ausencia de la aplicación (lápiz, papel y calculadora) u otra herramienta (planilla de cálculo, por ejemplo).

Otra característica de la aplicación que posiblemente deje residuo cognitivo, es la manera visual y paso a paso (iteraciones) de cómo se aplica el método. Este estímulo visual probablemente permitirá una mejor comprensión del método numérico y la asociación de nombre-algoritmo, más allá de la utilización de esta aplicación en particular. La visualización de la secuencia en forma de animación, se cree, podría reforzar el efecto antes descrito y, en ese caso, aportar al aprendizaje significativo de los métodos.

Los estudiantes de Cálculo Numérico utilizaron los dos primeros prototipos del software para el desarrollo de los trabajos prácticos relativos a la unidad temática Resolución de Ecuaciones no Lineales. También lo usaron para resolver algunos de los ejercicios sobre este tema incluidos en el primer examen parcial.

Con el objetivo de tener la opinión de los estudiantes matriculados en el curso de Cálculo Numérico sobre la utilización del software, en el 2009 se implementó una encuesta considerando los aspectos destacados en la Tabla 1.1 Ésta fue respondida en forma anónima y sus resultados se muestran en la Tabla 1.2.

\begin{tabular}{|c|c|c|}
\hline \multicolumn{2}{|l|}{ Preguntas } & Respuestas ( 10 encuestados) \\
\hline $\begin{array}{l}\text { 1. ¿Le pareció intuitivo el fun- } \\
\text { cionamiento del software utilizado? }\end{array}$ & $\begin{array}{c}\mathrm{Si} \\
8\end{array}$ & $\begin{array}{c}\text { No responde } \\
2\end{array}$ \\
\hline $\begin{array}{l}\text { 2. Las opciones en las que ingresa } \\
\text { los datos para aplicar el método, ¿le } \\
\text { parecieron claras? }\end{array}$ & $\begin{array}{l}\text { Si } \\
10\end{array}$ & $\begin{array}{c}\text { No responde } \\
0\end{array}$ \\
\hline $\begin{array}{l}\text { 3. Cada uno de los gráficos que rep- } \\
\text { resentan las diferentes iteraciones, } \\
\text { ¿favorecen la comprensión de los } \\
\text { métodos? }\end{array}$ & $\begin{array}{l}\mathrm{Si} \\
9\end{array}$ & $\begin{array}{c}\text { No responde } \\
0\end{array}$ \\
\hline $\begin{array}{l}\text { 4. ¿Tuvo inconvenientes con la sin- } \\
\text { taxis de las ecuaciones a solu- } \\
\text { cionar? }\end{array}$ & $\begin{array}{c}\mathrm{Si} \\
0\end{array}$ & $\begin{array}{c}\text { No responde } \\
0\end{array}$ \\
\hline $\begin{array}{l}\text { 5. ¿Utilizó las ayudas que presenta } \\
\text { el software? }\end{array}$ & Si & No responde \\
\hline & 8 & 0 \\
\hline $\begin{array}{l}\text { 6. ¿Utilizó el software sólo en las PC } \\
\text { de la Facultad? }\end{array}$ & $\begin{array}{c}\mathrm{Si} \\
6\end{array}$ & $\begin{array}{c}\text { No responde } \\
0\end{array}$ \\
\hline
\end{tabular}


7. ¿Considera que la utilización del software fue positiva para la comprensión de los métodos de resolu-

Si

10

No

0

No responde

0

ción de ecuaciones no lineales?

8. La información que apareció en 9. Cree que facilitó la comprensión
de:

10. Recurrió al software para:
11. Considera que el software es útil
para:
pantalla fue: para:

\section{obtener valores \\ numéricos de los métodos}

Clara
la aplicación
práctica de los métodos

resolver varios

ejercicios además de

los indicados en el

práctico

10

12. ¿Ingresó a alguno de los links relacionados con los autores de los métodos que aparecen en el software?

\section{Confusa}

1

$\begin{array}{cc}\text { la teoría de los } & \begin{array}{l}\text { Ningún } \\ \text { métodos }\end{array} \\ \text { aspecto }\end{array}$

5

0

resolver sólo los

ejercicios indicados

en el práctico

4 analizar el

funcionamiento para ninguno

gráfico de los de los casos

métodos

7

0

$\begin{array}{ccc}\text { Si } & \text { No } & \text { No responde } \\ 1 & 9 & 0\end{array}$

Tabla 1.2: Respuestas a las encuestas realizadas

Además de las respuestas a las preguntas formuladas en la encuesta, los estudiantes tuvieron la posibilidad de agregar comentarios que creyeran necesarios. Así fue que 6 de los 10 estudiantes participantes dejaron los aportes que se muestran en la Tabla 1.3.

\section{Complete con cualquier consideración que crea necesaria}

En lo personal me ayudó mucho. Por ejemplo, cuando tenía que indicar el intervalo donde se encontraba la raíz o raíces. La representación gráfica me permitía tener una primera aproximación de donde estaba la raíz y así no darle un valor inicial que haga que el método diverja.

Con respecto a la pregunta 5 sobre las ayudas, intenté usarlas pero me tiraba error la página, no se si se solucionó pues no he intentado nuevamente. Sobre la pregunta 8 que se refiera a la información en pantalla es confusa en un primer momento ya que tira muchos datos además de los gráficos que hacen difícil el análisis en una primera instancia, pero luego de ir familiarizándose con el software se hace más comprensible y legible toda la información que se muestra.

La ayuda a veces no anda.

Me facilitó muchísimo el trabajo. Me ahorró tiempo en graficar funciones que me demandarían mucho trabajo.

El recurso presentado en la página me facilitó además de la comprensión de los métodos vistos, la corrección de las producciones propias hechas en octave. 
No tengo otra consideración.

Tabla 1.3: Comentarios de los estudiantes

Si bien las respuestas mostraban la aceptación del software por parte de los estudiantes, también hubo aspectos señalados que provocaron la realización de ajustes en los próximos pasos en los que el software se amplió con la inclusión de nuevas unidades temáticas de Cálculo Numérico (Ascheri et al, 2011 y 2012).

\subsection{Version final del software}

A partir de la evaluación realizada, de la experimentación del software en varias oportunidades y de encuestas implementadas, se llegó a la versión actual del software en el que se incluyen los contenidos que se muestran en la Figura 1.3

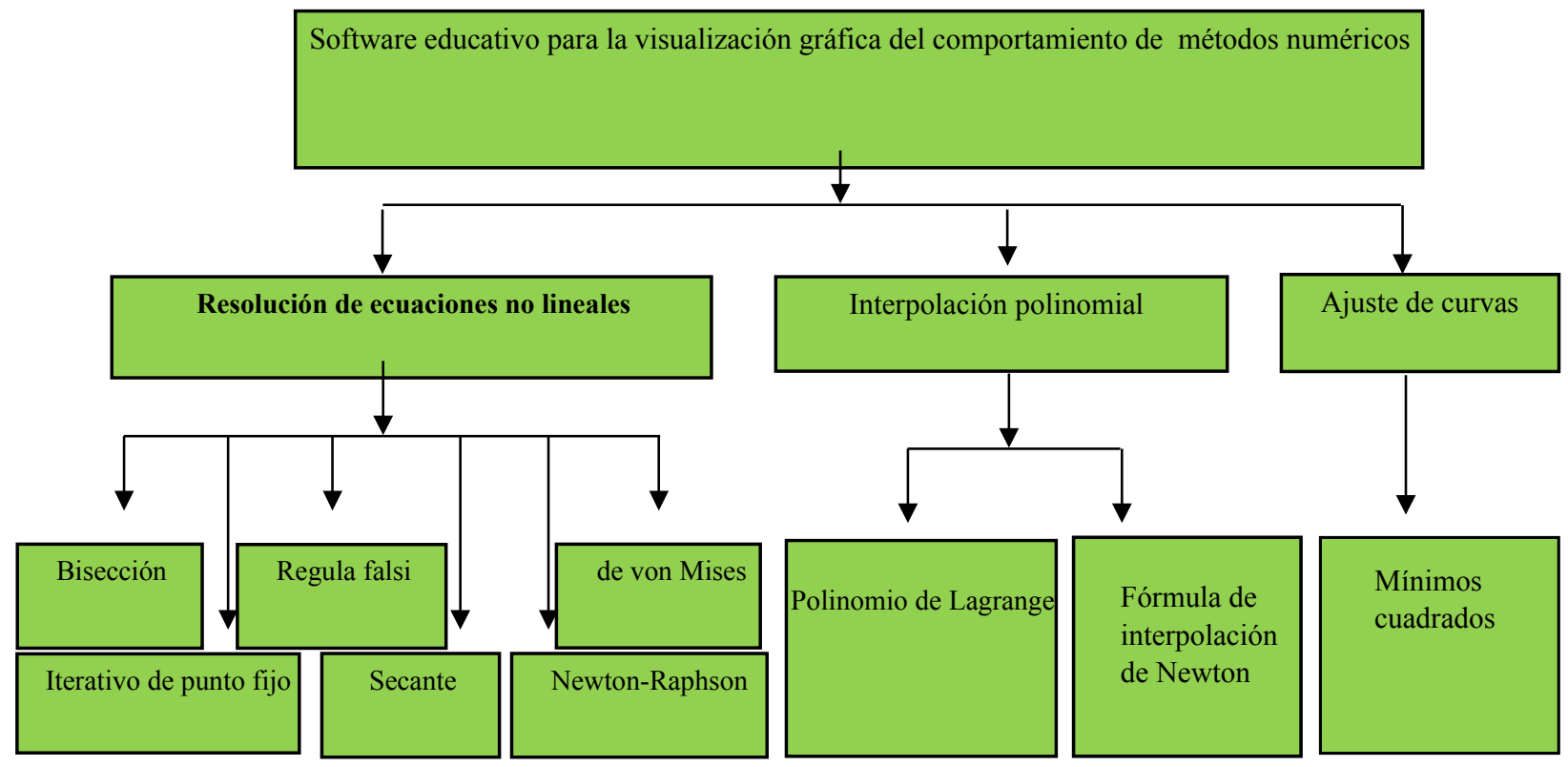

Figura 1.3: Cuadro de contenidos que aborda el software desarrollado

Seguidamente, se hace una síntesis de los resultados que ofrece el software educativo (http:// secanu. exactas.unlpam.edu.ar/).

$\mathrm{Al}$ ingresar, el estudiante se encuentra con la posibilidad de elegir entre las opciones Cálculo de raíces, Interpolación y Ajuste de curvas representadas por tres botones de colores distintos que distinguen los colores del ambiente al que ingresan. También, cuenta con una ayuda e información sobre el proyecto (Acerca de...). En la base de la página, se incorporó un enlace a un sitio Web de encuestas que permite recabar información sobre uso de la aplicación por parte de usuarios del software. La pantalla se muestra en la Figura 1.4. 


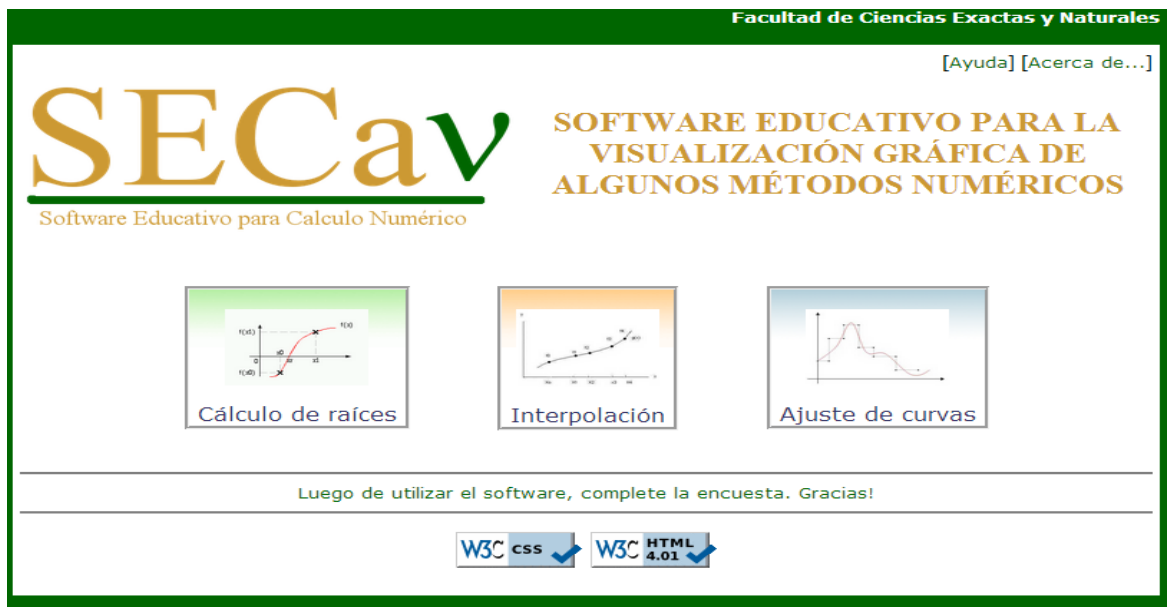

Figura 1.4: Pantalla inicial del software

Ingresando a la opción "Cálculo de raíces", se puede acceder a cualquiera de los seis métodos disponibles (Figura 3). Al seleccionar, por ejemplo, el método de "Newton-Raphson" la aplicación muestra una ventana en la cual se deberán ingresar los datos necesarios para implementarlo y elegir si desea ver la solución gráfica o sólo la numérica (Figura 1.5).

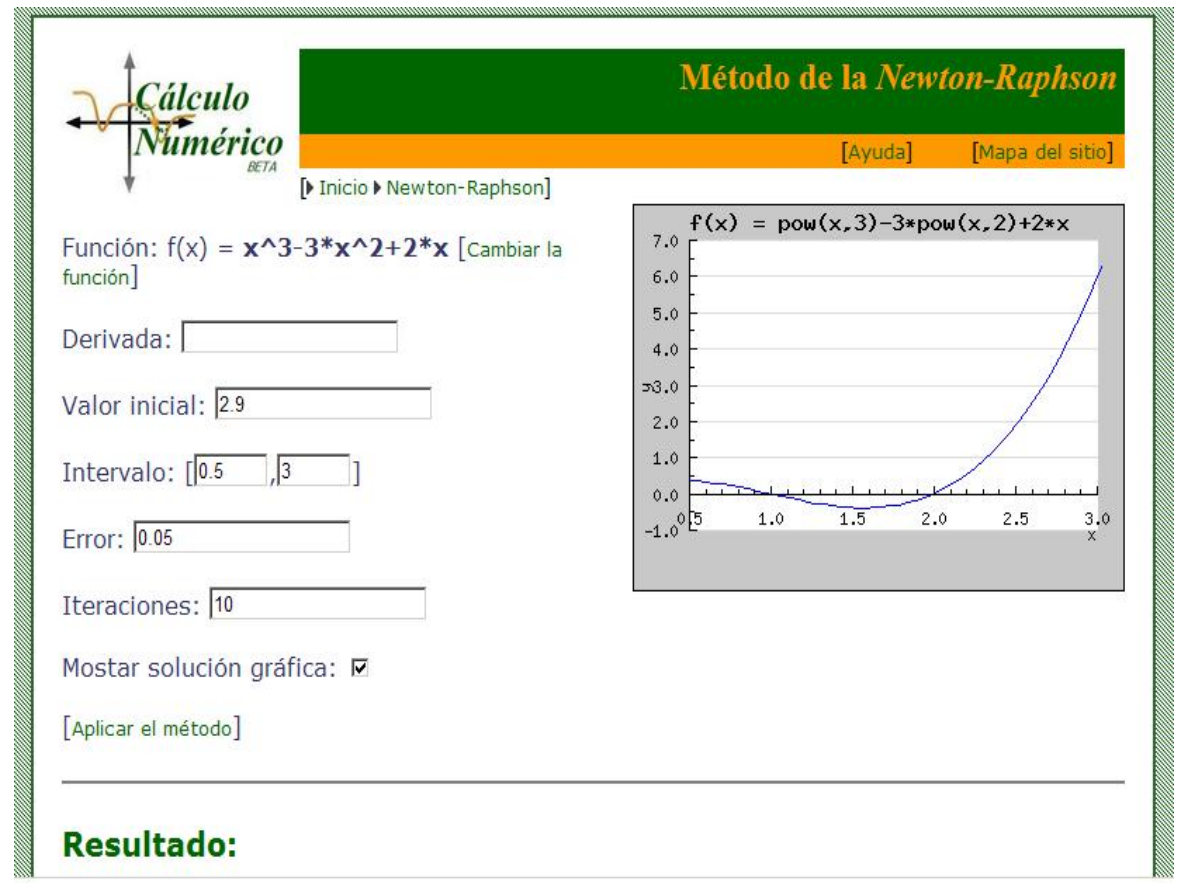

Figura 1.5: Pantalla del método de Newton-Raphson

Al seleccionar la opción "Aplicar el método", se obtienen sucesivas imágenes en las cuales se representan la gráfica de la función y las correspondientes aproximaciones a la raíz que se está buscando, como así también los resultados numéricos que se van obteniendo en las sucesivas iteraciones (Figura 6 (a) y (b)). Finalmente, se muestran los resultados numéricos relacionados con la resolución del problema 
propuesto (Figura 7). Si se elige alguno de los otros métodos, el software responde de manera similar de acuerdo al problema a resolver.

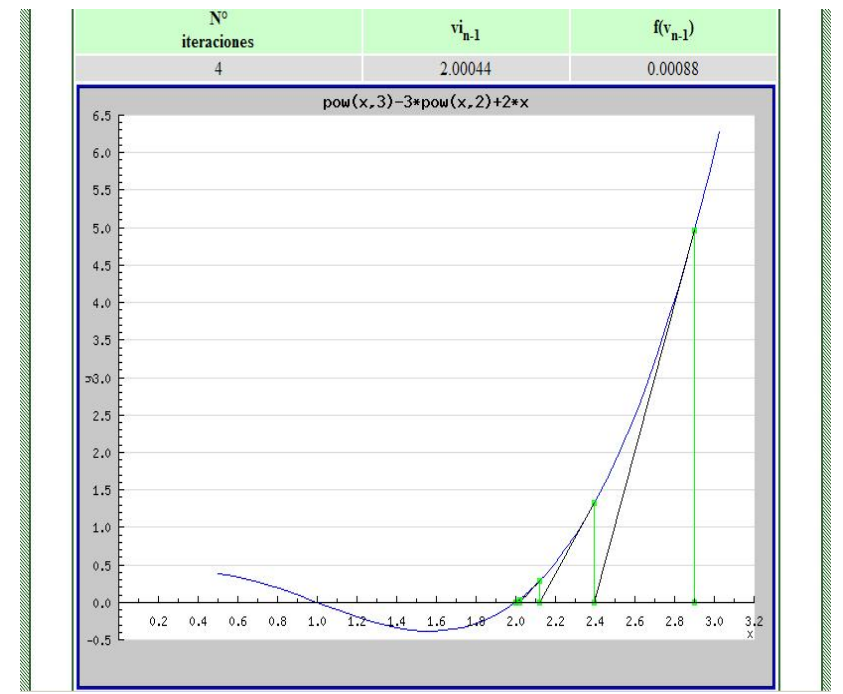

(a): Gráfica de la función y las correspondientes aproximaciones

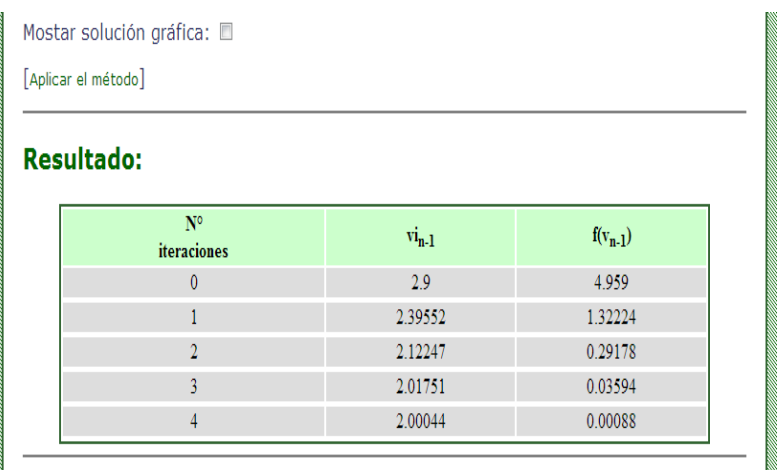

(b): Resultados numéricos iterados

La raiz de la ecuación es : 2.00044181423

El valor de la función en la raiz es: 0.00088421414573059

La cantidad de iteraciones necesarias son: 4

Figura 1.6: Resultados numéricos finales

Si al iniciar el software (Figura 1.4), se elige la opción "Interpolación" y se selecciona, por ejemplo,

"Polinomio de Lagrange", se obtiene la pantalla que se muestra en la Figura 1.8.

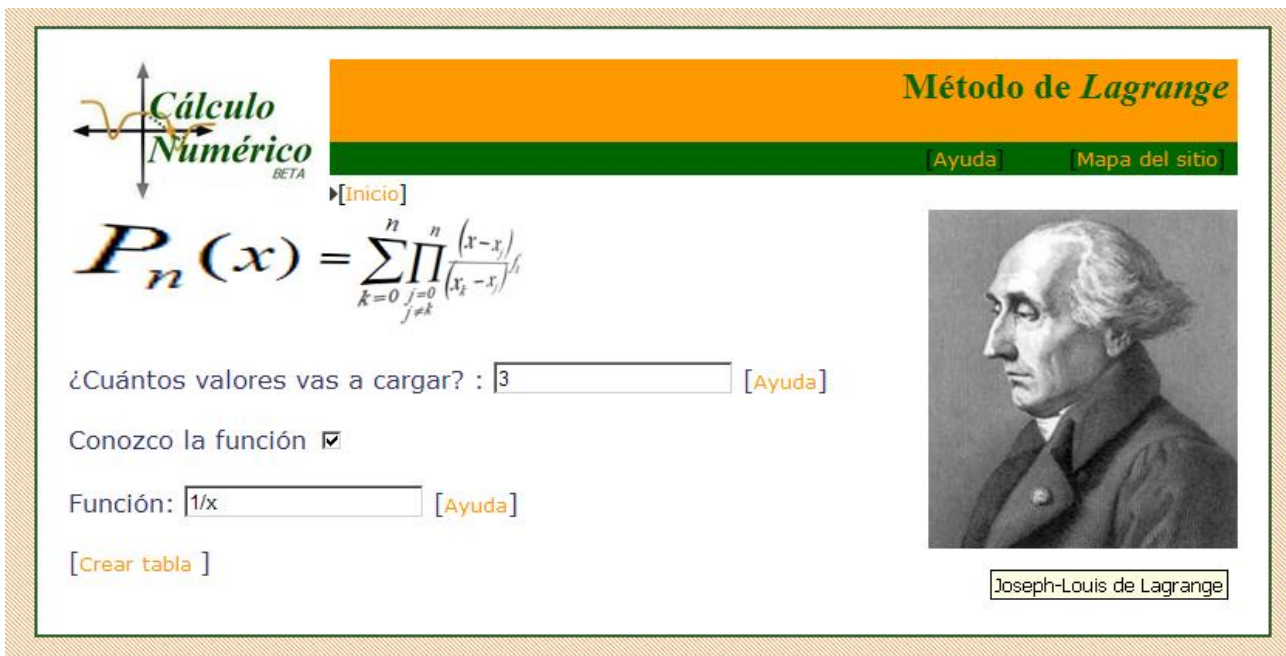


Figura 1.7: Pantalla inicial del método de Lagrange

Ingresando la función o los valores en los cuales se conoce la misma y el valor a interpolar, se obtienen los resultados que se muestran en las Figuras 1.9 y 1.10 (numérico y gráfico).

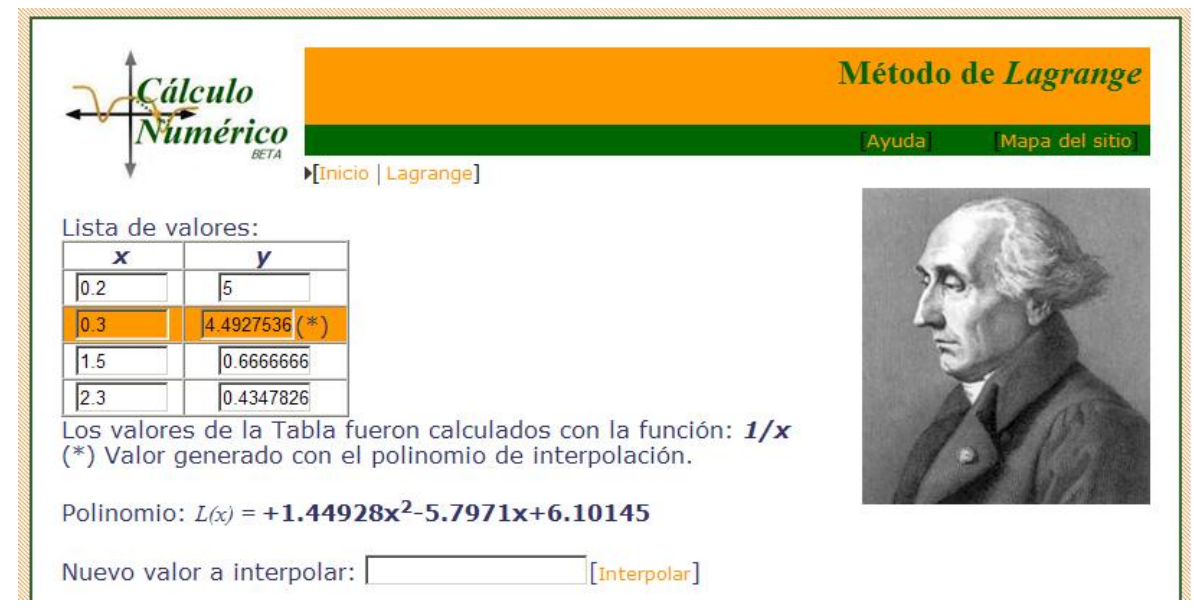

Figura 1.8: Selección de datos a interpolar

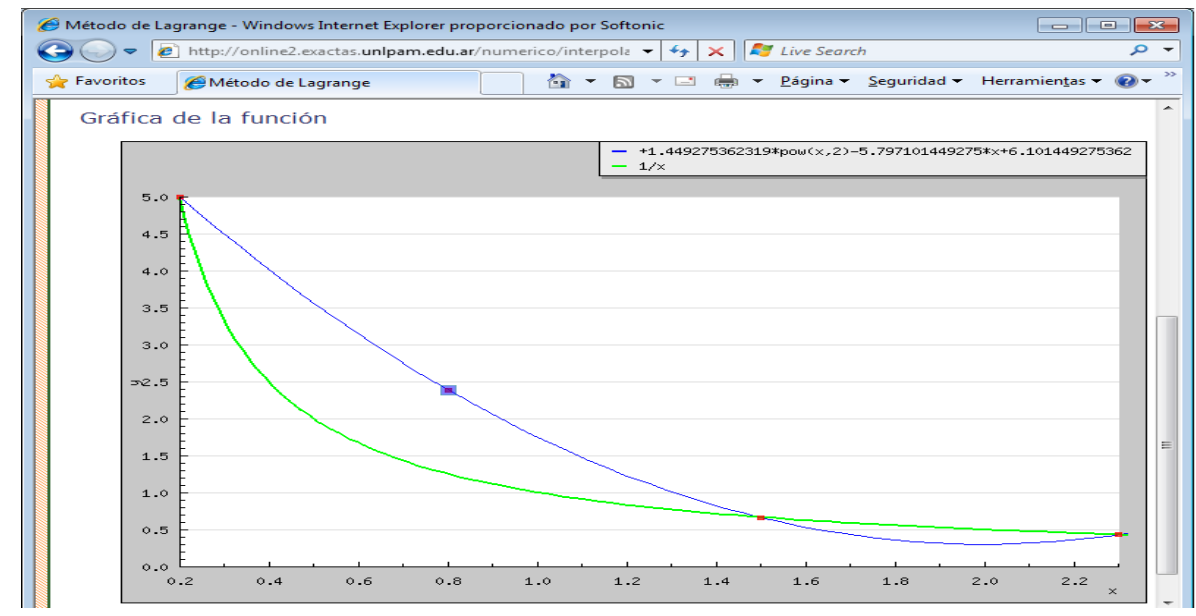

Figura 1.9: Gráfico de la función y del polinomio de interpolación

Análogamente, al iniciar el software se puede seleccionar la opción "Ajuste de curvas" (Figura 1.4), a partir de la cual se ajusta una curva por el método de mínimos cuadrados. Previamente, se debe ingresar la cantidad de puntos que se conocen y luego, la tabla de valores. Se obtiene así la representación gráfica de los puntos ingresados (Figura 1.11). 


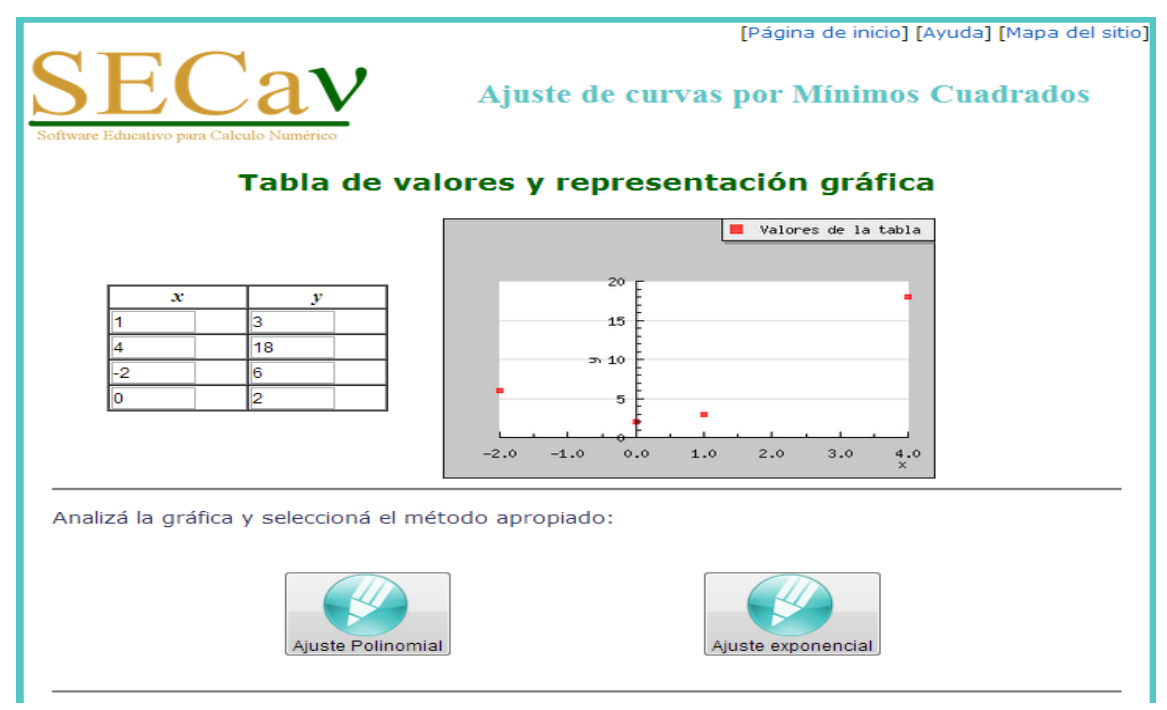

Figura 1.10: Gráfica de los puntos ingresados como datos para ser ajustados

Luego se procederá a seleccionar el tipo de ajuste que se desea aplicar (polinomial o exponencial). De esta forma, se obtendrá la función que ajusta los puntos ingresados como así también su gráfica (Figura 1.12).

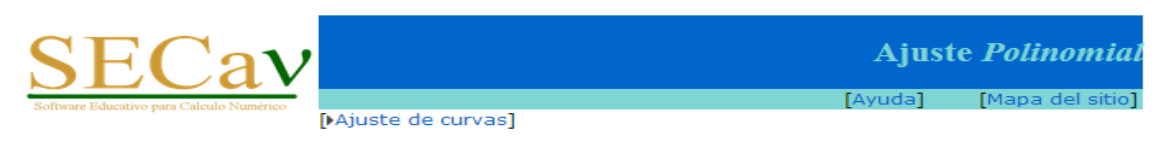

Lista de valores:

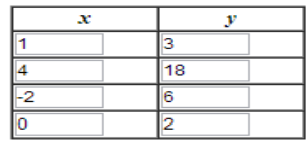

A partir de la tabla se obtiene la siguiente expresión:

$P(x)=+1 \mathbf{x}^{2}+2$

Gráfica de $P(x)$

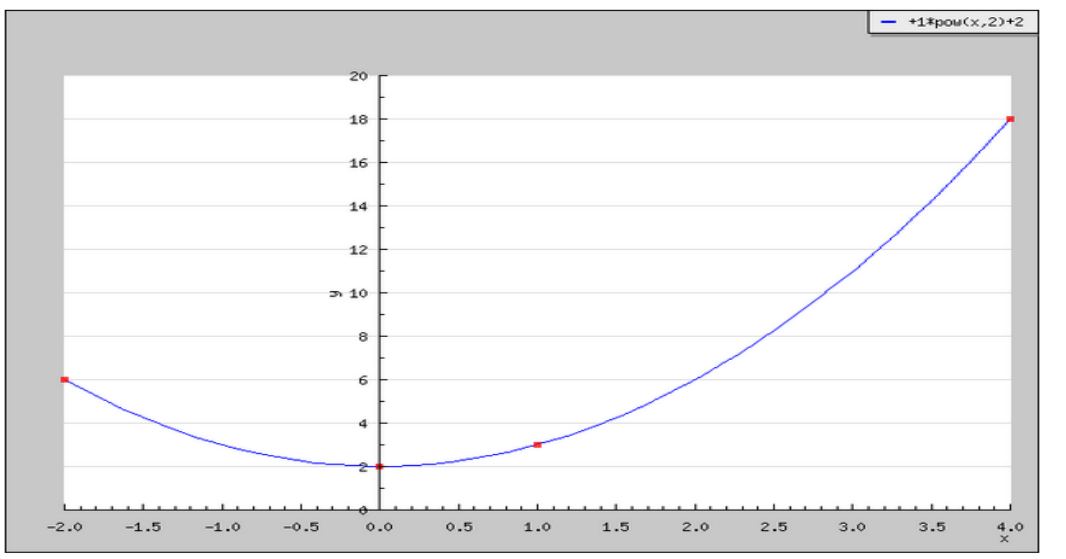

Figura 1.11: Obtención de la función que ajusta los datos ingresados 


\subsection{Utilización del software en clases}

Como se desprende del análisis anterior, es necesario considerar una serie de requerimientos para aplicar el software educativo. Una vez que el usuario los establece, verá si la respuesta obtenida es adecuada o no, de acuerdo al problema que espera resolver. Con ello, se pretende que el estudiante haga una revisión de los conceptos teóricos para analizar por qué un método está funcionando o no, cuál de los métodos resulta más adecuado para resolver el problema en cuestión y hacer un análisis gráfico de cómo se obtienen los resultados.

Resulta evidente que la aplicación de elementos gráficos realiza un importante aporte al proceso de enseñanza y de aprendizaje. El volumen de información que el estudiante recibe es mayor y de mejor calidad en determinados casos. Por ejemplo, podemos invertir mucho tiempo en describirle a un estudiante un paisaje determinado, pero mostrarle material fotográfico generará un nivel de percepción enormemente mayor, además de proporcionar una calidad de aprendizaje diferente. En informática, se han utilizado y desarrollado herramientas gráficas con el objetivo de facilitar las tareas de análisis y diseño de sistemas por consideraciones similares. En matemática, el análisis de la forma gráfica en cómo se comportan las funciones se encuadra en el mismo renglón. Como opinan Suárez y Cordero (2005), la graficación permite articular el uso de la modelación y de la tecnología en actividades matemáticas. Adicionalmente, según Zazkis et al (1996), mostrar el comportamiento analítico y visual de forma integrada puede ser necesario para comprender mejor ciertos conceptos matemáticos.

Este software educativo es utilizado en las clases teóricas y prácticas. En estas últimas, se resuelven ejercicios de los trabajos prácticos y de las evaluaciones parciales (ver Anexos I y II), mientras que para el desarrollo de la teoría, se usa como herramienta pedagógica colaborativa para la interpretación geométrica de los métodos numéricos estudiados, para el planteo y desarrollo de nuevos ejemplos, entre otras actividades.

\subsection{Resultados obtenidos}

Luego de cinco años de utilizar este software educativo en el curso de Cálculo Numérico, se obtuvo información sobre el impacto del mismo en el desarrollo de las clases. Se realizaron encuestas y se registraron observaciones de clases, además de considerar los resultados obtenidos en las evaluaciones parciales.

Del análisis de las encuestas realizadas en los años 2009 y 2011, se puede decir que los estudiantes, en su gran mayoría, señalan:

- Es muy positivo la inclusión del software en el desarrollo de las clases.

- El software me facilitó la comprensión de los diferentes métodos vistos.

- Me resultó fácil comprender su funcionamiento.

- Es muy importante poder acceder al mismo por medio de Internet, porque no tengo que instalar software adicional en mi computadora y además, lo puedo usar fuera de los horarios de cursado.

Las respuestas a las encuestas fueron positivas. Sin embargo, de las observaciones de las clases se pueden señalar los siguientes aspectos: 
- La mayoría de los estudiantes siguen utilizando la calculadora por sobre las herramientas informáticas para la realización de cálculos.

- Ante la posibilidad de realizar reiterados intentos con diferentes valores en el software, existe una tendencia a quedarse con el primer resultado obtenido, lo que dificulta la extracción de conclusiones.

A partir de la encuesta realizada en el año 2011, se dedujo que los estudiantes usaron las ayudas de la aplicación y el software fuera de la Facultad (figura 1.12).

15.

Utilizó las ayudas que presenta el software

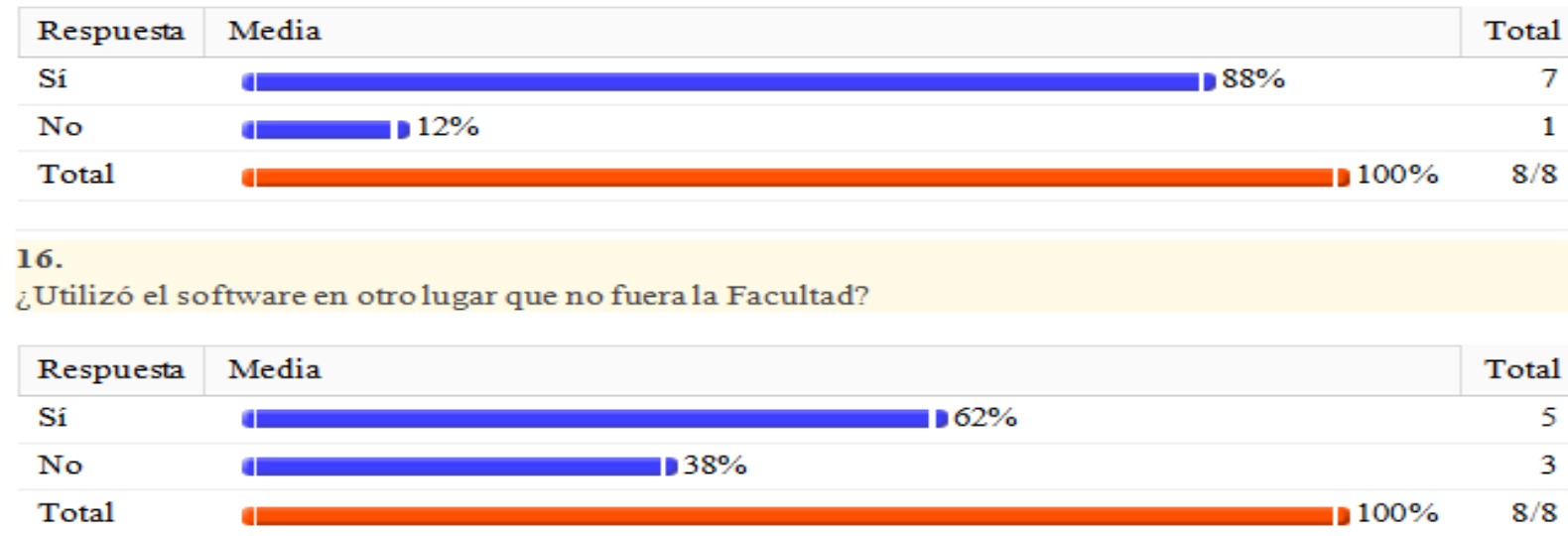

Figura 1.12: Respuesta de los estudiantes en la encuesta

En la Tabla 1.4, se muestran las diferentes opiniones de los estudiantes sobre la utilización del software educativo durante el desarrollo de la materia en el año 2012. Se preguntó: ¿Considera que la utilización del software fue positiva para la comprensión de los métodos de resolución de ecuaciones no lineales? Justifique su respuesta.

\section{Respuestas}

- Sí, porque muestra el resultado al que uno debe llegar y gráficamente muestra como resuelve cada método implementado

- Si, tal vez por la rapidez de los cálculos que a mano llevan más tiempo hacia que uno se pueda enfocar en el análisis de los mismos... y no preocuparse en la resolución...o en un posible error de cuentas.

- Sí, sobre todo para ver una solución gráfica y para corroborar resultados

- Creo que la explicación teórica estuvo clara pero al momento de la práctica es útil para ahorrarse un montón de cálculos. 
- Si, ya que te brinda las soluciones detalladas por cada iteración y los resultados en caso de que no llegues al objetivo manualmente... así podes entender el comportamiento de cada método...

- Si... sobre todo porque, particularmente, no estoy a favor de realizar cálculos repetitivos y tediosos a fin de hallar algún tipo de solución, sino que el verdadero sentido se encuentra en poder comprender para que sirve, así como las utilizaciones a futuro que se puede dar. por otro lado, es muy interesante la comparación entre los distintos métodos y mediante la utilización del programa se podrían establecer estos tipos de análisis comparativos.

- Totalmente, el software funciona eficientemente para la comprensión e interpretación de los métodos, la representación gráfica de cada uno de ellos ayuda mucho

- A modo de comprobación, o también para entender como trabajaba el error de la formula de Newton cuando no conocía la función.

Tabla 1.4: Opinión de los estudiantes sobre la utilización del software

Por lo que expresan los estudiantes en las diferentes instancias, se puede decir que si bien conocen y acuerdan con la incorporación de TIC en sus actividades de estudio, reconocen tener ciertas dificultades en el uso de las computadoras, en la mayoría de los casos, por no tener experiencias previas. Sólo la han utilizado en la realización de actividades complementarias u optativas. Esto coloca a las computadoras en un rol secundario y no como una herramienta de apoyo para construir sus aprendizajes.

A partir de la inclusión del software en las diferentes actividades académicas y, en consecuencia, de la correspondiente modificación de la metodología utilizada para el desarrollo de estas actividades, y considerando el número de estudiantes que cursan Cálculo Numérico por cada ciclo académico, se puede afirmar que se han obtenido resultados satisfactorios en lo que se refiere al número de estudiantes que han aprobado la materia. Es así que el promedio de la cantidad de estudiantes que en los últimos tres años aprobaron la materia es del $72 \%$, contra el $54 \%$ en las instancias anteriores (también considerando los últimos tres años cuando no se usaba el software).

Como integrantes de la cátedra de Cálculo Numérico y del grupo de investigación, se puede afirmar que trabajar en este software ha permitido incorporar herramientas de programación y contar en la actualidad con nuevos instrumentos didácticos para el desarrollo de los contenidos temáticos.

\subsection{Conclusiones}

El software educativo que se ha elaborado es una aplicación gratuita que se ejecuta en un entorno Web con mínimos requerimientos. Este software puede ser utilizado para la enseñanza y el aprendizaje de métodos numéricos, donde se muestra de forma numérica y gráfica el comportamiento de los mismos. La aplicación se denomina "Software Educativo para Cálculo Numérico" y se denota SECa

Si bien ha sido positiva la implementación de este software en el desarrollo de Cálculo Numérico, aún la utilización de las computadoras no es considerada por los estudiantes como un proceso natural; siguen priorizando el uso de lápiz, papel y calculadora. Dado que esta materia se cursa en tercer año del Profesorado en Matemática, los estudiantes han transcurrido al menos 15 años en un sistema 
educativo en el cual, en sus actividades, mantienen tareas netamente tradicionales. La mayoría de estos estudiantes serán Profesores de Matemática de Nivel Medio y encargados de incorporar nuevas formas de enseñar y aprender, por lo cual sus experiencias con la inclusión de tecnologías en sus clases deberían ser más frecuentes, pudiendo de esta forma aceptar y mejorar su manejo de la computadora y de diferentes software. Las nuevas políticas diseñadas para la inclusión de TIC demandan que los profesores estén capacitados para usarlas. Con la realización de experiencias como la del presente trabajo, se trata de aportar a este objetivo.

Continuar con la elaboración del software educativo ampliando los contenidos a desarrollar, incorporándolo a otras asignaturas y analizando la metodología de trabajo, son seguramente líneas de trabajo que permitirán una aproximación al logro de los cambios en Educación que se pretenden conseguir. Se cree necesario investigar cuál es el impacto del uso del software en el rendimiento académico de los estudiantes, por lo que se incluye también este tema entre las futuras líneas de investigación.

\section{Bibliografía}

[1] Ascheri, M. E. y Pizarro, R. A. "Software para la enseñanza - aprendizaje de algunos métodos numéricos". VII Edumat (pp. 1-10). Chivilcoy: EMAT Editora. 2005.

[2] Ascheri, M. E. y Pizarro, R. A. "Uso de tecnología en la enseñanza-aprendizaje de temas de Cálculo Numérico". CLAME, Vol. 19 (pp. 879-885). México. 2006. También disponible en http://www.clame . org. $\mathrm{mx}$

[3] Ascheri, M. E., Pizarro, R. A., Astudillo, G. J., García, P. y Culla, M. E. "Relevamiento de software en línea para la enseñanza-aprendizaje de métodos numéricos. Herramientas para su desarrollo". V CIEMAC (pp. 20-24). Cartago. Costa Rica. 2007.

[4] Ascheri, M. E. y Pizarro, R. Libro de Texto para Estudiantes Universitarios: CÁLCULO NUMÉRICO. Santa Rosa: EdUNLPam. 2007.

[5] Ascheri, M. E., Pizarro, R. A., Astudillo, G. J., García, P. y Culla, M. E. "Un software educativo con herramientas libres y acceso Web para temas de Cálculo Numérico: un primer prototipo". II Reunión Pampeana de Educación Matemática (pp. 223-230). Santa Rosa: EdUNLPam. 2008.

[6] Ascheri, M. E., Pizarro, R., García, P., Astudillo, G. y Culla, E. "Software educativo para el tratamiento de algunos temas de Cálculo Numérico: Primera etapa de evaluación". XI Workshop de Investigaciones en Ciencias de la Computación (pp. 670-673). San Juan: Facultad de Ciencias Exactas, Físicas y Naturales de la UNSJ y RedUNCI. 2009.

[7] Ascheri, M. E., Astudillo, G., García, P., Pizarro, R. y Culla, E. "Elaboración de un software educativo usando herramientas gratuitas. Primeras evaluaciones". V Congreso de Tecnología en Educación y Educación en Tecnología (pp. 1-8). El Calafate. Argentina. 2010.

[8] Ascheri, M. E., Astudillo, G., García, P., Pizarro, R. y Culla, E. "Software educativo para temas de Cálculo Numérico: Interpolación y aproximación polinomial. Tercer prototipo". XII Workshop de Investigadores en Ciencias de la Computación (pp. 855-859). Rosario. Argentina. 2011.

[9] Ascheri, M. E., Pizarro, R., García, P., Astudillo, G. y Culla, E. "Inclusión de software educativo en Cálculo Numérico. Algunos resultados". 3as Jornadas de Educación Mediada por Tecnología (pp. 1-10). Viedma. Argentina. 2012.

[10] Baeza Yates, R. y Rivera Loaiza, C. Ubicuidad y Usabilidad en la Web. En http://www.dcc.uchile.

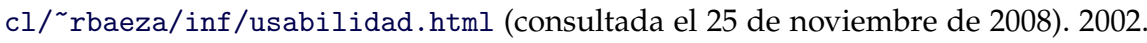

[11] Burbules, N. y Callister, T. "Riesgos y Promesas de las Nuevas Tecnologías de la Información". Educación. En Hipertexto: El conocimiento en la encrucijada (capítulo 3). Buenos Aires: GRANICA. 2001. 
[12] Díaz Antón, G., Grimán, A., Pérez, M. y Mendoza, L. Instrumento de evaluación de software educativo bajo un enfoque sistémico. En http://www. academia-interactiva.com/evaluacion.pdf (consultada el 10 de febrero de 2009). 2002.

[13] El Imperio del Número. Herramientas Matemáticas. Equation Solver. En http://es .numberempire.com/ equationsolver.php (consultada el 14 de octubre de 2013). 2013.

[14] Gómez Sánchez, R. "Software libre vs. Software propietario: Programando nuestro futuro". HAOL, 2, 125-140. 2004.

[15] Instone, K. Site Usability Evaluation - Part. 1. En http://instone.org/siteeval (consultada el 12 de noviembre de 2008). 1997.

[16] Instone, K. Site Usability Heuristics for the Web - Part. 2. En http://instone.org/heuristics (consultada el 19 de noviembre de 2008). 1997.

[17] Litwin, E. Las nuevas tecnologías y las prácticas de la enseñanza en la Universidad. En http://www. litwin.com.ar/site/Articulos2. asp (consultada el 26 de enero de 2009). 2001.

[18] Losada Liste, R. "GeoGebra: la eficiencia de la intuición". Gaceta de la Real Sociedad Matemática Española, 10 (1), 223-240. 2007.

[19] Marquès, P. El software educativo. En http://www.lmi.ub.es/te/any96/marques_software (consultada el 29 de abril de 2008). 1996.

[20] Mora, W. Métodos Numéricos. En http://www.tec-digital.itcr.ac.cr/revistamatematica/ cursos-linea/NUMERICO/index.htm (consultada el 15 de noviembre de 2012). 2011.

[21] Pizarro, R. A. y Ascheri, M. E. "Diseño e implementación de un software educativo en cálculo numérico", TEEET'07 (pp. 34-42). Red de Universidades Nacionales con Carreras en Informática, UNLP. La Plata. Argentina. 2007.

[22] Prieto Castillo, D. "La comunicación en la educación". En Comunicación con los medios y materiales (capítulo 6). Buenos Aires: Ciccus, La Crujía. 1999.

[23] Quintana Mendoza, J. y Mendoza Bolo, M. Guía para el desarrollo del pensamiento a través de la matemática. Perú: Fimart S.A.C. 2006.

[24] Rodino, A. M. "Las nuevas tecnologías informáticas en la educación: viejos y nuevos desafíos para la reflexión pedagógica". VII Congreso Internacional sobre Tecnología y Educación a Distancia (pp. 51-71). Costa Rica: EUNED. 1996.

[25] Santandreu, P. M. Recursos TIC en la enseñanza y aprendizaje del área de matemáticas. Comunicación y pedagogía: Nuevas tecnologías y recursos didácticos, 200 (pp. 65-70). 2004.

[26] Solve My Math. En http: //es . solvemymath. com/ (consultada el 20 de octubre de 2013). (2006-2011).

[27] Sternberg, R. J. (ed.) Handbook of Human Intelligence. CUP Archive. 1982.

[28] Squires, D. y Mc Dougall, A. Choosing and using educational software: a teachers' guide. London: The Falmer Press. 1994.

[29] Suárez, L. y Cordero, F. "Modelación en matemática educativa". En J. Lezama, M. Sánchez y J. Molina (Eds.), Acta Latinoamericana de Matemática Educativa 18, 639-644. México: Comité Latinoamericano de Matemática Educativa. 2005.

[30] Villegas, F. "TIC y Matemáticas". Unión: revista iberoamericana de educación matemática, 9, 149-163. En http://www.fisem.org/paginas/union/info.php?id=186 (consultada el 19 de febrero de 2009). 2007.

[31] W3C. W3Counter. Global Web Stats. En http://www.w3counter.com/globalstats.php (Consultada el 29 de noviembre de 2013)

[32] Zazkis, R., Dubinsky, E. y Dautermann, J. "Coordinating visual and analytic strategies: a student's understanding of the Group D4". Journal for Research in Mathematics Education, 27 (4), 435-457.1996.

[33] Zhao, Y. "Blind Trust in Authentic Mathematical Tools in Mathematics". Education. The International Journal of Computers Algebra in Mathematics Education, 3, 161-173. 1998. 


\section{Apéndice A}

\section{Ejercicios tipo de los trabajos prácticos que incluyen el uso del software educativo}

1. Utilizando el software disponible en http://secanu . exactas . unlpam.edu . ar/ aplicar los métodos de bisección, de la secante y de Newton-Raphson para calcular raíces reales de una ecuación no lineal y con una cota de error admisible de $1 \times 10^{-5}$, de las ecuaciones:
a) $\ln x+64-e^{x}=0$
d) $\operatorname{sen} x-\ln x=0$
b) $\ln x-(x-3)^{2}+2=0$
e) $\left(x^{2}+1\right) e^{-x}-x=0$
c) $x^{3}+3 x^{2}+1=0, I=[-4,0]$
f) $x-0.8-0.2 \operatorname{sen} x=0 ; I=[0, \pi / 2]$

2. Utilizando el software disponible en http://secanu. exactas. unlpam.edu.ar/ encontrar las tres raíces de la ecuación $-x^{3}+4 x^{2}-e^{x}=0$ aplicando los métodos de la secante, de la bisección e iterativo de punto fijo con una cota de error admisible de 0.005 .

3. Obtener el polinomio de interpolación que pase por los puntos: $(0,5),(2,1),(3,13),(6,57)$

a) Mediante la fórmula de Lagrange.

b) Mediante la fórmula de Newton para diferencias divididas.

c) Verifique los resultados obtenidos en los apartados a) y b) utilizando el software disponible en http://secanu. exactas. unlpam. edu.ar/ 
4. Sea $f(x)=\frac{e^{x}}{x-1}$.

a) Obtener el polinomio de interpolación de Lagrange, utilizando el software de la página http://secanu.exactas.unlpam.edu.ar/, considerando $x_{1}=1.5, x_{2}=2$ y $x_{3}=3$.

Según este gráfico, ¿en cuál de esos valores se comete mayor error? Comprobarlo analíticamente.

b) Considerando el ejercicio del apartado a), obtener el polinomio de interpolación de Newton con diferencias divididas, utilizando el software de la página http://secanu.exactas. unlpam.edu.ar/, considerando $x_{1}=1.5, x_{2}=2$ y $x_{3}=3$.

Según este gráfico, ¿en cuál de esos valores se comete mayor error? Comprobarlo analíticamente.

c) ¿Qué conclusión puede obtener de comparar los resultados logrados en a) y b)?

5. Utilizando el software disponible en http://secanu.exactas.unlpam.edu.ar/ se pide obtener la aproximación a $f(1.5)$ considerando la siguiente tabla:

\begin{tabular}{c|c}
$x$ & $f(x)$ \\
\hline 1.0 & 0.7651977 \\
1.3 & 0.6200860 \\
1.6 & 0.4554022 \\
1.9 & 0.2818186 \\
2.2 & 0.1103623 \\
\hline
\end{tabular}

6. Estimar la población de los años 1945 y 1975 considerando la siguiente tabla que muestra la población de EEUU desde 1930 a 1980.

\begin{tabular}{ccccccc}
\hline Año & 1930 & 1940 & 1950 & 1960 & 1970 & 1980 \\
\hline Población (en miles) & 123.203 & 131.669 & 150.697 & 179.323 & 203.212 & 226.505 \\
\hline
\end{tabular}

a) Graficar los polinomios de interpolación obtenidos

b) Indicar el error cometido en cada uno de los cálculos. 


\section{Apéndice B}

\section{Ejercicios tipo de una evaluación parcial que incluyen el uso del software educativo}

Ejercicio 1. Utilizando el software disponible en http://secanu . exactas . unlpam.edu .ar/ eencontrar una de las raíces de la ecuación $x^{3}+4 x^{2}-8=0$ aplicando el método de Newton-Raphson y la restante con el método iterativo de punto fijo. Completar luego la siguiente tabla:

\begin{tabular}{|c|c|c|c|c|c|c|}
\hline Método & $x_{0}$ & Error & No iterac. & Raíz & $\begin{array}{c}\text { Últimas tres } \\
\text { iteraciones }\end{array}$ & $\begin{array}{c}\text { Función } \\
\text { generadora }\end{array}$ \\
\hline $\begin{array}{c}\text { Newton } \\
\text { Raphson }\end{array}$ & & 0.005 & & & & \\
\hline $\begin{array}{c}\text { Iterativo } \\
\text { de punto } \\
\text { fijo }\end{array}$ & & 0.005 & & & & \\
\hline
\end{tabular}

Ejercicio 2. Utilizando el software disponible en http://secanu.exactas.unlpam.edu.ar/ y conociendo los siguientes valores

\begin{tabular}{|c|c|c|c|c|c|c|c|c|}
\hline $\boldsymbol{x}$ & 1.5 & 3.2 & 4.8 & 5.9 & 7 & 7.9 & 8.5 & 12 \\
\hline $\boldsymbol{y}$ & 3.25 & 8.28 & 9.29 & 10.5 & 15 & 10.2 & 8 & 3.4 \\
\hline
\end{tabular}


a) Indicar el polinomio de interpolación correspondiente y el método por el que fue obtenido.

b) Interpolar $x=2.3,5.3,8.2,9.8$. 